Article

\title{
Decide Madrid: A Critical Analysis of an Award-Winning e-Participation Initiative
}

\author{
Sonia Royo *(1), Vicente Pina $₫$ and Jaime Garcia-Rayado $₫$ \\ Department of Accounting and Finance, Universidad de Zaragoza, 50005 Zaragoza, Spain; \\ vpina@unizar.es (V.P.); jgrayado@unizar.es (J.G.-R.) \\ * Correspondence: sroyo@unizar.es
}

Received: 7 February 2020; Accepted: 18 February 2020; Published: 24 February 2020

check for updates

\begin{abstract}
This paper analyzes the award-winning e-participation initiative of the city council of Madrid, Decide Madrid, to identify the critical success factors and the main barriers that are conditioning its performance. An exploratory case study is used as a research technique, including desk research and semi-structured interviews. The analysis distinguishes contextual, organizational and individual level factors; it considers whether the factors or barriers are more related to the information and communication technology (ICT) component, public sector context or democratic participation; it also differentiates among the different stages of the development of the initiative. Results show that individual and organizational factors related to the public sector context and democratic participation are the most relevant success factors. The high expectations of citizens explain the high levels of participation in the initial stages of Decide Madrid. However, the lack of transparency and poor functioning of some of its participatory activities (organizational factors related to the ICT and democratic dimensions) are negatively affecting its performance. The software created for this platform, Consul, has been adopted or it is in the process of being implemented in more than 100 institutions in 33 countries. Therefore, the findings of this research can potentially be useful to improve the performance and sustainability of e-participation platforms worldwide.
\end{abstract}

Keywords: e-participation; local government; information and communication technologies (ICTs); citizen participation; transparency

\section{Introduction}

In the last few decades, the public sector has evolved from government to governance, a policy framework with high levels of cooperation with external stakeholders in both policy design and service delivery [1,2]. Developments in Information and Communication Technologies (ICTs) have contributed to this transformation by promoting higher communication with citizens, informing, educating and empowering citizens and reducing the costs of the decision-making process [3,4].

E-participation can be defined as the use of ICTs to involve citizens and other stakeholders in public decision-making processes and policy deliberation to make public administrations participatory, inclusive, collaborative and deliberative for intrinsic or instrumental ends [5]. The adoption of e-participation has increased in the last decades at the worldwide level. From 2003 to 2018, the percentage of countries with an e-participation index higher than $75 \%$ has grown from $3 \%$ to $32 \%$, whereas those with an index below $25 \%$ have reduced from $77 \%$ to $18 \%[6,7]$.

E-participation is supposed to have multiple benefits, such as communicating with a wider audience, increasing the knowledge of participants about public issues, allowing a more informed and deeper participation and improving the quality of public policies and citizens' trust in government [8]. However, empirical analyses show that e-participation initiatives have usually failed to deliver these benefits [9-14]. Achieving engagement and meaningful collaboration through digital technologies 
requires a better understanding of what hinders governments and citizens from being able to effectively collaborate, both online and offline [15]. Barriers to effective citizen participation include poor public knowledge of the issues treated, poor provision of information, poor execution of participatory methods, low adoption, the digital divide, lack of representativeness of participants, lack of political support, failure to influence the decision-making processes, regulatory constraints or the use of these tools for political propaganda [14-18]. Moreover, public administrations are often not clear about the objectives of these initiatives. All of this can give rise to different types of tensions and conflicts, disappointment and reluctance to engage in future processes [19].

Most previous literature has analyzed e-participation platforms that only allow one type of e-participation activity or occasional participation. Therefore, more research regarding critical success factors for citizen participation platforms aimed at fostering long-term government-to-citizen and citizen-to government relationships is needed. Furthermore, despite the increasing scientific and practical relevance of e-participation, many questions remain open and the understanding of successful e-participation initiatives is very limited [20]. Current good practice should be highlighted in order to ensure there is wider take-up and inspiration [17]. In addition, a reduced number of studies have analyzed individual level factors (as compared to contextual and organizational factors) and/or the institutionalization stage of e-participation (as compared to its adoption and implementation) [21].

To fill these gaps, this research analyzes an a priori exemplary e-participation initiative to identify the critical success factors and the main barriers that are conditioning its performance. The analysis is carried out by taking three different approaches: (1) distinguishing among contextual, organizational and individual level factors; (2) considering whether they are more related to the ICT component, public sector context or democratic participation; and (3) differentiating among the different stages of development of the initiative (adoption, implementation and institutionalization). The performance of the platform is assessed in terms of participation levels, democratic legitimacy, transparency, influence on decision-making processes and continuity. This comprehensive analysis will allow a more complete discussion about success factors and barriers for effective e-participation.

The e-participation initiative chosen is the Decide Madrid platform (Madrid city council, Spain), launched in 2015. Decide Madrid was one of winners of the 2018 United Nations Public Service Award. This award assessed, among 111 nominates, (1) the introduction of an innovation, (2) the fight against discrimination and the encouragement of equality, (3) the promotion of a robust legal framework and (4) participatory decision-making [7]. This platform is also listed in the OECD Observatory of public sector innovation (see https://oecd-opsi.org/case_type/opsi/). This initiative includes some of the most popular e-participation tools (e-forum, e-consultation, e-voting and online participatory budgets) in a single platform created and managed by the city council. Until the end of 2018, more than 400,000 users were registered, being participatory budgets the tool that has attracted the highest level of participation. The software created for this platform, Consul, has been adopted-or it is in the process of being implemented-in more than 100 institutions from 33 countries that build a collaboration network. Porto Alegre, the first city in the world that implemented participatory budgets in 1989, adopted Consul in August 2018 in order to implement its first online participatory budgets and online polls. So, this research focuses on an example that could be considered a good practice in e-participation and a source of inspiration for practitioners worldwide. However, as the critical analysis carried out in this research shows, some areas for improvement also exist that should carefully managed to improve its performance and sustainability.

\section{Background, Theoretical Framework and Analytical Model}

\subsection{Background and Theoretical Framework}

Background. Research in e-participation can be classified as (1) barriers and facilitators and (2) strategies for the adoption, implementation and/or institutionalization of e-participation [21]. Both dimensions are covered in this research. The methodologies most used in e-participation research 
are surveys and content/discourse analyses [22]. The methodology used in this paper, the case study, is a third approach. According to Reddick and Norris [23], e-participation research should consider the use of qualitative methods, such as case studies, to gather more in-depth information about e-participation and its impacts. Most of the case studies published to date refer to a particular e-participation activity (e.g., references [14,24-26]), e-forums being the most common one. The analyses of e-participation platforms that allow different types of e-participation activities are testimonial [27].

Overall, research in e-participation shows that several factors may determine the success or failure of e-participation initiatives, such as the legal framework, funding, organizational structure and culture, commitment by politicians, administrators and staff, the complexity of e-tools, security and privacy issues, the combination with offline activities, the communication and promotion plan, the moderation of debates, the degree of inclusiveness and transparency-related issues (e.g., references [14,15,17,22]). However, their importance in the different stages of development of e-participation initiatives has not been considered. Panopoulou et al. [17] list the factors that should be considered to ensure the proper implementation and operation of an e-participation initiative and to maximize its potential for success. Furthermore, Toots [14] highlights the need to manage three types of challenges: those typical to ICTs projects, those emerging from the public sector context and those related to democratic participation. All these factors and challenges are considered in this research.

Theories explaining the adoption and institutionalization of e-participation. Citizen participation initiatives can be adopted due to legal requirements or on a voluntary basis. Therefore, the adoption of e-participation can be explained by using institutional theory. According to this theory, institutions tend to adopt similar structures through three types of isomorphism [28]: coercive (pressure imposed on an organization by legal, hierarchical or resource dependence), mimetic (imitation of practices of leading organizations in an attempt to achieve greater recognition) and normative (environmental pressure for transformation from stakeholders). Mergel [29] found that best practice examples and comparisons with other entities were used by government organizations to adopt social media and Pina et al. [30] that local governments implement e-participation to strengthen the ties among the local community rather than to achieve actual improvements in environmental programs (mimetic isomorphism). The diffusion of citizen participation in local governments has also been explained by the need to comply with legislation (coercive isomorphism) [31].

Theories explaining the adoption and implementation of e-participation. Stakeholder theory can also explain the adoption and development of e-participation initiatives [24,31]. According to this theory, organizations should identify their different stakeholders and fulfil their needs and expectations in order to succeed. Previous literature has found that most citizens do not use e-participation tools or mainly use them to access information, whereas those who seek to influence decision-making processes usually reduce their participation over time [24]. Voluntary participants have high expectations about their participation and the same reasons that mobilized them can lead to disappointment [19]. The commitment to e-participation from other stakeholders usually depends on their role. For example, politicians show more levels of participation before elections, whereas civil servants and private companies are more committed before the initiative is launched, because they participate to a greater extent in its development and implementation [24].

The behavior of citizens in e-participation can be also explained by networked individualism, which describes how people connect and communicate in the new social system of online relationships [32]. Networked individualism describes a "new pattern of sociability" where people build and manage multiple sets of personalized, mutable networks and identities to meet their needs [33]. According to this theory, people tend to participate in many different groups, but with reduced levels of commitment to any of them, in general terms [32]. Its application to e-participation anticipates that citizens would be easily involved in different e-participation initiatives. However, sustaining citizen commitment to long-term e-participation processes will be more difficult than in offline processes and there is a real risk that levels of participation will decrease over time [30,34]. 


\subsection{Analitical Model}

Previous e-participation research has identified several success and failure factors, but well-developed explanatory frameworks and more systematic evaluation of e-participation initiatives are needed [14,16]. Different analytical frameworks have been proposed to analyze citizen participation and e-participation initiatives. Gelders et al. [35] propose an analytical framework with conditions for successful citizen participation classified in seven areas: participation and collaboration (constructive relationship between all parties), resources (staff and other), policy involvement (support of the municipality), communication, context, method (choice of the right method and its proper implementation) and continuity.

Porwol et al. [36] propose three not mutually exclusive perspectives to analyze e-participation initiatives: democratic (assessment of the democratic context of e-participation initiatives, such as transparency, political utility and objectives), project (assessment of project management issues, such as organizational change, stakeholders and outcomes) and sociotechnical (information about participatory activities on the platform, such as topics, tools, timelines and monitoring). Kubicek and Aichholzer [37] propose a generic input-activities-output-outcome-impact model (project and sociotechnical perspectives) to evaluate e-participation processes. Inputs, activities and outputs refer to the evaluation of the offer and resources by the organizing entity; outcomes cover the demand side component (number, profile and activities of the participants and the characteristics of the contributions made, for example) and impacts are the final consequences of the participatory process (e.g., changes of attitudes or behavior, higher trust in political institutions, learning, building of social capital and so on). Toots [14] presents a model of four factors (context, e-participation system, project organization and stakeholders) to explain the failure of e-participation systems that also covers the three perspectives defined by Porwol et al. [36].

The analytical model used in this case study (see Figure 1) is based on the model designed by Randma-Liiv and Vooglaied [38], which also covers the factors identified in the three above-mentioned perspectives and avoids the overlapping of factors among different categories. It is made up of five main elements of analysis: context, e-participation initiative, organizational factors, individual factors (actors) and evaluation of the initiative. Some other models introduce more complicated interactions among the constructs to be analyzed. For example, for Toots [14] the effect of contextual factors on information systems is not direct, but mediated by organizational factors and stakeholders' reaction. However, given the exploratory nature of research, with no hypothesis or theoretical statements to test, the analytical model refers to the elements to be analyzed, without going into the details of possible mediating effects among the constructs.

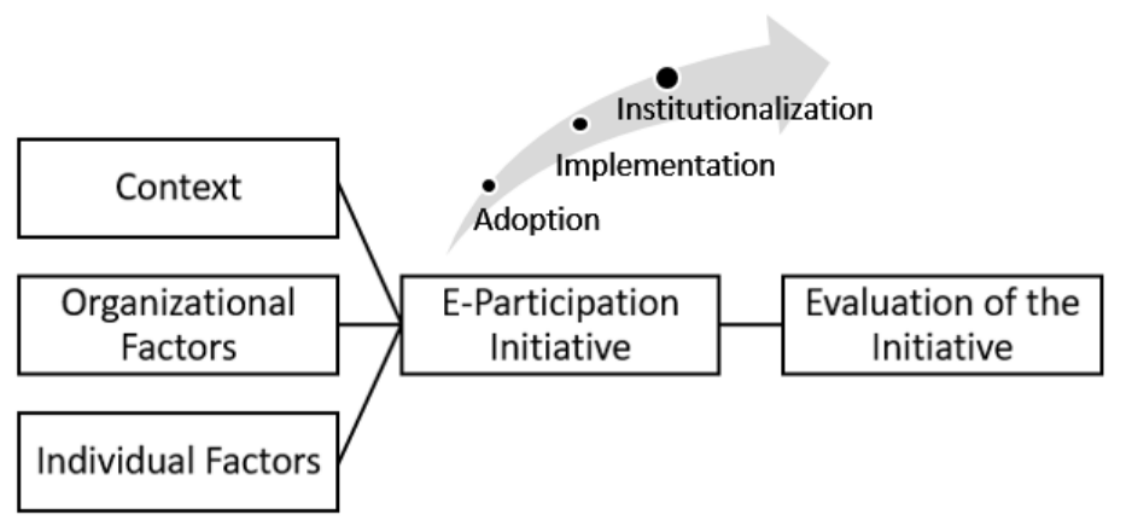

Figure 1. Analytical model. Note: Adapted from Randma-Liiv and Vooglaied [38] (p. 16).

An exploratory case study has to specify what is to be explored, the purpose of the exploration and the criteria by which the exploration will be judged successful or not [39] (p. 29). The first four elements of analysis (context, organizational factors, individual factors, and e-participation 
initiative) define what is to be explored to identify the critical success factors and main barriers. The context analyzes the following aspects: cultural-historical framework, socio-economic, digital governance and politico-administrative factors, legal requirements and civil society. The e-participation initiative analyzes the goals, scope, chronology, legal framework and technical features of Decide Madrid. Organizational factors include aspects related to the ownership and administration of the platform, partners, internal collaboration arrangements, funding, human resources and organizational processes and culture. Individual factors (actors) cover the analysis of both internal (leaders and administrators) and external (other formal or informal actors outside the city council structure) actors. As the evaluation of whether e-participation is successful or not cannot be judged in absolute terms [37], five criteria are used. Four of them (performance indicators, democratic legitimacy, transparency of the process and influence on decision-making processes) were taken from Randma-Liiv and Vooglaied [38]. The continuity condition from Gelders et al. [35] was added as it is important to look beyond the actual project and focus in the long term. Examples of successful practices and failures are also provided in the last unit of analysis. Lastly, a contribution of this work, that is not included in the analytical model designed by Randma-Liiv and Vooglaied [38], is the discussion of the importance of each of the identified success factors and barriers in the different stages of development of the initiative (adoption, implementation and institutionalization) and whether they are more related to the ICT component, public sector context or democratic participation.

\section{Methodology}

This study uses an exploratory case study as main research technique. A case study is appropriate when examining contemporary phenomena within its real life context, especially when the boundaries between phenomenon and context are not evident and the intervention being evaluated has no clear, single set of outcomes [39]. The main strength of this method is its ability to deal with multiple sources of evidence, such as documents, interviews and observation, allowing the researcher to mix qualitative and quantitative evidence. The data and information used in this case study were obtained through desk research and semi-structured interviews with politicians, civil servants and users of the platform. The combination of different data sources has allowed us to triangulate data and assess the success of the initiative according to different points of view. The disadvantage of this methodology is that the results are not statistically generalizable. Notwithstanding this, they provide insights to inform theory and guidance to practitioners [14,39].

Desk research included the analysis of the Decide Madrid platform (main website and related data provided in the open-data and transparency portals of the Madrid city council), statistical data from Eurostat, the Spanish Institute of Statistics (INE) and the Spanish Centre for Sociological Research, relevant legal documents at national and local level (such as "Law 57/2003, on Measures for the Modernization of Local Governments" and "the Organic Regulation of Citizen Participation of the Madrid City Council") and other related reports issued by international organizations and governmental bodies (such as the "E-government survey" from the United Nations or the "E-government in Spain" report from the European Commission).

To understand citizen participation processes, we cannot simply examine the tools or rely on document analysis; we must understand the role of citizens, stakeholders and public administrators who are the tool makers and tool users [40]. So, in December 2018, nine semi-structured interviews (see Table 1) were carried out following the structure of the analytical model presented in Figure 1. The interviews lasted for around $1.5 \mathrm{~h}$ and were recorded for further analyses.

The importance of each source of information is different in the analysis of each dimension of the analytical model. The information needed to describe the e-participation initiative was obtained mainly from Decide Madrid and Consul websites. Information about contextual factors was obtained mainly from desk research. Information about organizational and individual factors was obtained from the interviews to politicians and civil servants and desk research (legal documents about the organizational structure of the city council and competences of different departments and units, human resource 
reports and the city council website). Citizen interviews are relevant in the qualitative evaluation of the initiative (together with the interviews to politicians and civil servants) and data from the open-data portal in the quantitative evaluation (i.e., number of users, activity in the platform and so on).

Table 1. Interviewees.

\begin{tabular}{cl}
\hline Politician 1 & Politicians of the governmental area in charge of Decide Madrid \\
\hline Politician 2 & \\
\hline Civil servant 1 & Senior civil servant of the general directorate in charge of Decide Madrid \\
\hline $\begin{array}{cl}\text { Civil servant 2 } \\
\text { Civil servant 3 }\end{array}$ & Technical staff of the general directorate in charge of Decide Madrid \\
\hline Citizen 1 & User of Decide Madrid and member of a municipal association \\
\hline Citizen 2 & User of Decide Madrid affiliated to the political party which promoted this initiative \\
\hline Citizen 3 & Users of Decide Madrid \\
\hline
\end{tabular}

Note: Contacting with users of Decide Madrid was a main difficulty. Data protection legislation did not allow the city council to provide us with users' contact data and most users of Decide Madrid do not disclose their complete name. In order to find citizens' contact data, we looked for complete names in the accounts of the most active users in the last six months. Then, we searched on the Internet for the email addresses or social media accounts of these users to ask for their cooperation and arrange an interview. In any case, the number of citizens interviewed does not intend to be representative of all the users the platform, but proportional to the other interviewees.

In order to analyze the external institutionalization of the Consul software, the links to all the initiatives listed in the Consul website (http://consulproject.org/en/) were checked. Fifty-one e-participation platforms were active by mid-January 2020 and they were analyzed to determine the e-participation options they have adopted. This has allowed us to assess whether full mimetic isomorphism in the institutionalization of this software has taken place or whether subsequent adopters are using only certain e-participation options depending on their needs or local circumstances.

Lastly, the limitations of this study should be acknowledged. The purpose of this paper is not to produce generalizable results for all e-participation initiatives in the public sector. Rather, the objective is to contribute with some additional findings to the limited literature on citizen participation platforms aimed at fostering long-term government-to-citizen and citizen-to-government relationships. Case studies are a commonly adopted form of obtaining information but they are not intended to achieve any kind of representativeness, so any generalization of the results must be carried out with caution, particularly in regards to citizens' opinions, due to the reduced number of citizens that could be interviewed. However, as the results of the case study will show, citizens opinions were rather similar, which strengthens their validity.

\section{Case Study}

\subsection{Context}

Since the 1990s, the digitalization of administrative processes has been a priority in Spain [41]. Spain occupies high positions in e-government (16th position in 2002 and 17th in 2018) and e-participation indexes (5th position in 2018) [7,42]. Spain has also been a member of the Open Government Partnership (OGP) since its inception in 2011.

The use of ICTs by citizens in Madrid exceeds the national average [43]. Data for 2017 show that 91.7\% of the households in Madrid have broadband internet connection. Furthermore, Madrid has traditionally ranked above the average in e-government empirical studies (e.g., reference [44]). Madrid has also long experience in neighborhood-based associations that collaborate with the municipality in the co-production of public services [45].

In Spain, the possibility of direct citizen participation in public affairs and individual or collective petitions is recognized in the 1978 Constitution (art. 23 and 29). Law 57/2003 introduced specific ICT procedures to facilitate the effective participation of citizens in local public life matters and Law 
40/2015 introduced the requirement for local governments to carry out online public consultations. The minimum support needed for citizens' initiatives in Spanish municipalities with more than 20,000 inhabitants is $10 \%$ of the citizens (art. 70bis of Law 57/2003). The participation of citizens in Madrid is regulated by an Organic Regulation approved in 2004 and subject to subsequent modifications. Some previous municipal regulations (1988 and 1992) about citizen participation existed even before the legal requirement established by Law 57/2003. This regulation established the right of citizens, entities and collectives to participate in local governance, with no specific mention to e-participation. In regards to individual citizens, it includes the right of citizens to information, public consultation, public audience, participation in the formulation of public policies as well as to make petitions and proposals, among others.

The worldwide financial crisis, the governmental austerity policies, and the cases of corruption lowered citizen trust in politics. This situation led to the protest of thousands of people in many countries. In Spain, the greatest was the "15M movement", which evolved into new political parties, "Podemos" being the most representative. In Madrid, it formed a coalition with other political parties under the name of "Ahora Madrid" that governed the city from May 2015 to May 2019. "Ahora Madrid" included in its electoral program a commitment to "implement tools for citizen participation through the Internet [ ... ]", and created Decide Madrid to implement this commitment. Moreover, Madrid city council, that joined the Subnational Government Pilot Program of the OGP in 2016, has been a formal member of this organization since 2017, promising to develop participatory budgets and collaborative and efficient legislative mechanisms, and to expand the policy of citizen participation [46]. Madrid also participates in other networks that foster citizen participation at local level such as Sustainable Cities Platform, Local Governments for Sustainability and the Covenant of Mayors.

\subsection{Decide Madrid e-Participation Platform}

Decide Madrid was launched in September 2015. Its objective is "to encourage the participation of citizens in the management of the city, involving them in the generation of innovative and viable ideas and proposals, in order to improve their quality of life. It is a strong commitment to a management closer to citizens that allows the city council to receive citizens proposals and to create direct communication channels with citizens, helping managers to make the most appropriate decisions for the general interest" (translated from the Spanish version available at: https://decide.madrid.es/condiciones-de-uso). Decide Madrid is implemented only at Madrid city level, but the open source software developed, Consul, has been implemented or is in the process of being implemented in more than 100 organizations around the world, most of them in Europe (especially in Spain) and Latin America (see http://consulproject.org/en/). To create this platform, some examples of citizen participation were reviewed, especially Better Reykjavik (Iceland), Brazil (Porto Alegre) and Switzerland.

Participation in Decide Madrid can be carried out through five sections (debates, proposals, polls, processes and participatory budgeting, see Table 2). Citizens can participate in three moments of the policy cycle: (1) agenda setting, (2) policy analysis and preparation, (3) policy formulation and, to some extent, policy monitoring. In all cases, the topics eligible are only those under Madrid council competences.

The platform is open to everyone without registering, but participation is limited according to the different types of activities. Everyone, including associations, NGOs and companies, can be registered in the platform, create debates or proposals and make comments in all sections. However, only registered individual citizens of Madrid over 16 can verify their accounts and then they can create proposals for participatory budgeting and support and vote proposals. Decide Madrid is accessible to people with disabilities and the verification processes and almost all participatory activities can also be done offline in any of the 26 citizen attention offices, including the use of printed signature forms to collect support for the projects. 
The guidelines and procedures that support the working of this platform have been approved by different agreements of the city council since October 2015. However, the existence of Decide Madrid is not guaranteed by any law and depends on political will.

The Consul code, freely available on the Internet, allows any organization, public or private, to use and adapt the platform to its own needs. The improvements made by any organization or individual user can be exploited by the rest, fomenting collaboration between them. Madrid is the most significant driver of Consul but, according to Politician 2, it is expected to be more decentralized in the future.

Table 2. Types of participation in Decide Madrid.

\begin{tabular}{cl}
\hline Debates & $\begin{array}{l}\text { E-forum where users can post topics, comment or state agreement or disagreement. The city } \\
\text { council can also create debates. }\end{array}$ \\
\hline Proposals & $\begin{array}{l}\text { Users make a request which can be complemented by audio-visual materials and/or } \\
\text { supporting documents. Verified users can support the proposals and those proposals with the } \\
\text { support of } 1 \% \text { of the people over } 16 \text { registered as residents in Madrid (27,662 inhabitants at } \\
\text { 2018) are voted on. }\end{array}$ \\
\hline Polls & $\begin{array}{l}\text { Polls are carried out when a proposal receives } 1 \% \text { support or when the city council wants } \\
\text { citizens to decide on an issue. Polls can be open to all citizens or to the citizens of one district. }\end{array}$ \\
\hline Processes & $\begin{array}{l}\text { This tool is used by the city council to seek different types of input (e.g., to develop or modify } \\
\text { regulations, to request proposals for an activity). The way in which the processes are carried } \\
\text { out depends on the information that the city council needs (e.g., debates, provision of } \\
\text { documents in text format so that citizens can propose changes). }\end{array}$ \\
\hline Participatory budgeting & $\begin{array}{l}\text { Annually, citizens can decide directly on how a part of the next year's budget will be spent. } \\
\text { The projects can be for the whole city or for specific districts and they may affect current } \\
\text { expenditures, subsidies or public investments. Citizens can vote on projects for the whole city } \\
\text { and/or projects for only one district of their choice. }\end{array}$ \\
\hline
\end{tabular}

\subsection{Actors}

Internal actors. The Mayor Manuela Carmena was the main political leader of this initiative. She played an important role in the promotion of the initiative and the coordination of the areas involved. The city council decided that the results in polls and participatory budgets were binding, but this decision has no legal coverage, so the adoption of the results obtained is only ensured because all areas depend directly on the Mayor's Office, which acts in cases of disagreement. "[ .. ] The Mayor [ ... ] ensures that the rest of the areas are always committed to the project $[\ldots]$ it would not be the same without the Mayor commitment" (Politician 1).

The second political leader was the councilor responsible for the Citizen Participation, Transparency and Open Government Area. This person has wide experience in programming and has created and managed software companies. Another important political leader is the executive advisor and director of Decide Madrid. The executive advisor was one of the creators of Incoma, a software that allows debates between lots of people. According to the interviews, these three political leaders were those who decided the creation of Decide Madrid and the selection of the managers and staff. "The political level influences a lot [ ... ]. The executive advisor pays a lot of attention to the details $[\ldots]$ he likes to be involved in the details because he has the capacity to do it [ ... ]" (Civil servant 2).

Finally, the General Director of Citizen Participation, the administrative leader, is responsible for the day-to-day operations. This person has been a civil servant since 1981 and was an executive advisor in positions related to higher education and technology in the central government and in different public administrations.

External actors. Decide Madrid has no significant relationships with non-governmental leaders, media or international consultants. Promotors of Decide Madrid were only advised by Citizens Foundation (the non-profit organization that manages Better Reykjavik) about technical issues at the beginning of the initiative. The interviewees (Politician 1 and Civil servants 1 and 2) state that during the setting up of the platform and the development of the participatory processes, the platform has had two main detractors: the most important media in terms of audience (" $[.$. ] there has been a clear rejection and an attempt to very strongly delegitimize it on the part of the media [ ... ], not in an objective way 
because we have a fairly open policy of communication [ ... ]", Politician 1) and the two center-right political parties in the opposition. One of these political parties was against "direct democracy", so it opposes everything related to this platform, and the other criticized some of the methods of participation. For example, they question the reliability of the method to obtain support in the proposals section due to the speed with which some proposals get a lot of support and the confidentiality of the postal vote [47].

\subsection{Organizational Factors}

Decide Madrid was managed by the General Directorate of Citizen Participation (GDCP) whose competences were citizen participation and social innovation programs. This directorate belonged to the Citizen Participation, Transparency and Open Government Area, which depended directly on the Mayor's Office [48].

Actors that contribute to the functioning of the platform. At international and national level, the most important informal partners are the organizations using Consul, as they collaborate in improving the software and in the implementation of this platform around the world. Within the city council, all government areas and administrative units contribute to Decide Madrid by proposing topics and evaluating proposals made by citizens. The Service of Inclusion, Neutrality and Privacy is a particularly relevant actor to promote the participation of groups at risk of social exclusion [48]. Another relevant actor is "Medialab Prado" (https://www.medialab-prado.es/en/medialab) (a city council-owned company), a citizens' laboratory where some innovation projects related to Decide Madrid are being developed. The city council also contracts external companies for complying with the data protection law (e.g., encryption of votes to ensure anonymity).

Internal collaboration. Regulated collaboration with other areas of government occurs (1) for the verification process of the users' accounts, with the register of inhabitants; (2) for promotion tasks, the communication unit of the GDCP collaborates with the General Directorate of Communication, and (3) for offline activities related with Decide Madrid, with the Area of Government of Territorial Coordination and Public-Social Cooperation, which coordinates and promotes offline participation [48]. Other types of collaboration depend on the will of each area, staff motivation and the accountability structure.

Other services and departments collaborate by proposing topics for the processes/consultations and evaluating the proposals made by citizens. "The evaluation of the projects proposed by citizens is carried out by different government areas and districts [...] because they have the technical skills [...] those interconnections are needed so that everything works well" (Civil servant 2). This collaboration is particularly important for cost assessments. Costs evaluation in participatory budgets is very important: " [ ... ] there are many proposals in the first positions, but when people find out their cost they say no to them, it's not worth it, I prefer other things" (Civil servant 1). In response to citizen concerns about delays in the execution of participatory budgets, the city council is setting up a Participatory Budget Execution Office to improve the monitoring of approved projects, so the collaboration with other areas in the monitoring phase will be more formal.

The huge amount of proposals for participatory budgets to be evaluated increases the workload of other departments. Sometimes, citizens' proposals change their planning, priorities and ways of working. Consequently, according to the politicians and civil servants interviewed, at the beginning of Decide Madrid there was some resistance and complaints from the other units and services but now they are adapted to the new organizational culture: "It has supposed more workload for many civil servants [... Initially, they did not anticipate that citizen participation would imply additional work and there were some problems, but these have been solved now [ ... ] and there is a smooth collaboration" (Civil servant 1).

Financial resources. The development, implementation and the operational costs associated with Decide Madrid are funded by the city council's budget, so Decide Madrid is free for users. Decide Madrid also receives funds for its participation along with three other Spanish city councils in an open government project, funded with FEDER grants, which aims to improve the platform and create new modules. 
Politicians 1 and 2 and Civil servant 1 state that the funding has been sufficient in all the phases of development of Decide Madrid ("[ ... ] this general directorate has a budget [ ... ] in line to what we need [ ... ]", Civil servant 1), although Civil servant 2 thinks they need more funds: "the financial resources are not enough $[\ldots]$ but that always happens in public administration $[\ldots] "$. All the politicians and civil servants state that financial sustainability is guaranteed.

Human resources. The GDCP has approximately 40 civil servants, including administrative staff, lawyers, social workers, computer scientists and communications staff, together with three senior managers and advisors with different backgrounds (software companies, universities and public administration). However, according to Politician $1, "[\ldots]$ they are not only dedicated to the day-to-day operations of the city council projects; many people work in the external development, in connections with other countries or in more innovative or transversal projects. Such large teams are not needed [for running the platform]". The staff of the GDCP came from other governmental areas because the Citizen Participation, Transparency and Open Government Area was new. In order to recruit them, an open process for the city council personnel was established and individual interviews were carried out to ensure that the candidates were motivated and could adapt smoothly to the organizational culture that the managers wanted to develop. Furthermore, according to the interviewees (Politician 1 and Civil servants 1, 2 and 3), around 130 civil servants from other areas participate occasionally in the analysis and evaluation of proposals and approximately 10 interim civil servants, with different competences, depending on the projects in implementation phase, work temporarily in this area for the Participatory Budget Execution Office.

The interviewees highlight the importance of the knowledge of legal matters, advanced technologies and languages and of skills in dealing with citizens, indicating that the most lacking aspects are those of languages and advanced technologies. Sometimes, occasional staff are contracted for specific aspects, such as social media or platform developments. However, this is an unusual practice because the contracting process is slow and there are many restrictions on these types of contracts.

Organizational processes and culture. The GDCP and area of government in charge of Decide Madrid must follow the regular organizational processes as a part of the city council. Decide Madrid is embedded in the overall formal policy-making processes because other departments use the platform to carry out public consultations and public audiences. However, the GDCP shows some differences in decision-making processes, as the staff have more autonomy than in other areas. "We are between the citizens and the areas of government [ ... ]" (Civil servant 2). According to Politician 2 and Civil servant 1 , Decide Madrid has made a progressive change in the perception of the staff of other areas about direct citizen participation and the use of open-source software. Indeed, within the possibilities allowed by local and national regulation, the GDCP has generated a particular subculture within the city council, given the greater autonomy of its staff, the looser definition of jobs, more teamwork than in other departments and the staff commitment to citizen participation.

\subsection{Evaluation}

Performance indicators. Decide Madrid discloses aggregated statistics (number of supports and votes, percentage of participation by gender, age group, district, and via web or offline, when appropriate) both for the first polls (up to 2017, inclusive) and for the participatory budgets. For participatory budgets, the platform also provides data about which projects are technically unfeasible, under study/analysis, in processing, in execution or ended. Until July 2017, the GDCP published reports where the results of citizen participation in polls and participatory budgets were analyzed and the results of satisfaction surveys and suggestions and claims systems were included. Interviewees said that the GDCP has more information and has their own indicators, revised monthly for internal purposes. According to Politician 1, they focus on the number of users and participants, participation growth and impacts on the decisions of the city council (e.g., money spent on participatory budget projects). 
All the politicians and civil servants interviewed agree that there is a growing trend in terms of users, participation and impact of the participatory budgets, although some of the citizens interviewed think that the participation in proposals has decreased, which is consistent with the data reported in Table 3. The number of debates started per day and comments on those debates also present a decreasing trend. Up to the end of 2018, 25,418 proposals were made and only two of them reached the voting phase. In total, 13 polls at city level and 21 polls at district level have been carried out in three voting periods (February 2017, October 2017 and July 2018). In the first voting period, 214,076 citizens participated and 963,887 votes were counted (one citizen could vote on more than one issue), there were more participants by mail (54.0\%) than through Decide Madrid (35.1\%) and ballot boxes $(10.9 \%)$, but more votes were cast through the platform (49.3\%). In the second and third voting periods, participation decreased and there were only 92,829 and 9854 votes, respectively. The third voting period was only at district level and not all districts had projects. The reduction in the number of votes can also be explained by the fact that voting was only allowed through Decide Madrid and ballot boxes, the topics were less important and the polls were initiated by the city council.

Table 3. Statistics about activities carried out through Decide Madrid.

\begin{tabular}{|c|c|c|c|c|c|}
\hline & & 2015 & 2016 & 2017 & 2018 \\
\hline \multirow{2}{*}{ Proposals } & Registered & 6984 & 8074 & 5500 & 4860 \\
\hline & Reach enough support & 0 & 2 & 0 & 0 \\
\hline Polls & Number of polls & 0 & 0 & 19 & 15 \\
\hline \multirow{7}{*}{$\begin{array}{c}\text { Participatory } \\
\text { budgets }\end{array}$} & Number of participants & & 45,529 & 67,132 & 91,032 \\
\hline & Number of votes in final phase & & 32,725 & 38,866 & 53,891 \\
\hline & Projects initially presented & & 5814 & 3215 & 3323 \\
\hline & Final projects & & 206 & 311 & 328 \\
\hline & Budget (millions $€$ ) & & 60 & 100 & 100 \\
\hline & $\%$ of the municipal budget & & $1.2 \%$ & $1.8 \%$ & $1.8 \%$ \\
\hline & Euros per inhabitant & & 18.9 & 31.3 & 30.9 \\
\hline \multirow{2}{*}{ Debates } & Debates started per day & 37.8 & 1.5 & 1.1 & 0.7 \\
\hline & Comments per day & 151.5 & 21.9 & 7.2 & 6.5 \\
\hline Processes & Processes started & 6 & 5 & 36 & 23 \\
\hline
\end{tabular}

Source: Open-data platform of the city council of Madrid [49] and Decide Madrid website.

Democratic legitimacy. Even though the platform provides detailed information about how the different sections work, one of the citizens interviewed thinks that the methodology of participation through the platform does not allow the citizens an effective form of direct participation: " [ ... ] It does not achieve its objectives [ ... ] because a lot of citizens get lost in the website" (Citizen 1). All citizens interviewed agree that the most important motivation is the possibility of seeing their contributions implemented or taken into account. However, they note that they do not have enough information about the effect of their contributions and the progress of the projects already approved: "there should be a section with the actions carried out based on citizen participation [...]; there is a lack of feedback" (Citizen 2). The monitoring of citizen participation through the platform only covers participatory budgeting. In the other sections, citizens can only see other users' reactions (supports, assessments and votes).

Transparency. The users of Decide Madrid decide what is discussed in the platform in most cases, with the exception of the processes section. The politicians and civil servants interviewed give a lot of importance to free communication among users, so there is only a slight moderation to ensure there are no illegal comments (e.g., incitement to violence, insults or discrimination). Citizens can select other citizens' activities as inappropriate and moderators review them. Citizens are provided with information to facilitate their participation (e.g., technical reports, related laws ... ). However, some citizens think that the information provided is not enough or it is not presented in an understandable way. 
Influence on decision-making processes. According to Politician 1 and Civil servant 1 , there have been more than 1000 actions decided by citizens. The proposals in the polls and participatory budgets that go to a vote and win are implemented by the city council if they pass the same controls and additional studies applied to the rest of the projects of the city council. Sometimes the actions carried out may differ from those initially proposed by citizens, as some projects need to be defined in detail, further developed or limited in order to be under the competences and capabilities of the city council. For the other sections (debates and processes), the respective area analyzes citizens' comments and decides what to do, but no feedback to citizens is usually provided. However, the technicians interviewed indicate that some contributions of citizens to processes have resulted in changes in proposed policies and legislation (e.g., articles 9.6 and 15 of the Organic Regulation of the Observatory of the City and some commitments for the Second Open Government Action Plan of the City of Madrid). According to Citizen 1, Decide Madrid has increased citizen participation in Madrid (online and offline) and the platform has channeled associations' initiatives towards online participation. However, Citizens 2 and 4 think they can put less pressure on the municipal government online than offline and one of them thinks that the integration of associations in Decide Madrid is not enough.

Continuity and institutionalization of the Consul Software. Decide Madrid is still being used after the change of government in Madrid municipality that took place in June 2019; seven processes have been carried out from mid-June 2019 to mid-January 2020 and although the information about the participatory budget for 2020 is not yet available in the website at the time of writing this paper, the approved budget for 2020 foresees its execution. As said above, Decide Madrid is embedded in the city policy-making processes, has made a progressive change in the perception of the staff of other areas about direct citizen participation, internal collaboration with other departments has been high and all of them are adapted to the new organizational culture. Therefore, the institutionalization at internal level has been high and its continuity seems to be guaranteed for the time being.

As regards external institutionalization, the analysis of the 51 e-participation platforms carried out (see Table 4) shows that participatory budgeting is the most adopted tool (64.7\%). Proposals and polls have also been adopted by a relatively high percentage of entities $(56.9 \%$ and $45.1 \%$, respectively). Only 4 entities (7.8\%) have adopted the five e-participation options available in Decide Madrid, whereas six entities have developed new sections, mainly to provide information about offline citizen participation activities (such as events or volunteering options), but also to tailor the original e-participation options (by combining debates, proposals and processes that only the local government can initiate, in the case of Gran Canaria, Spain), or include other e-participation tools ("interview the governor" in the State of Jalisco, Mexico). The most common adoption pattern is to implement just one of the e-participation options ( $35.3 \%$ of the entities opt for this), and almost $80 \%$ of the entities have adopted $1-3$ of the e-participation options.

Table 4. E-participation tools adopted by other users of the Consul software $(\mathrm{N}=51)$.

\begin{tabular}{cccccc}
\hline Debates & Proposals & Polls & Processes & Participatory Budgeting & Other \\
\hline 20 & 29 & 23 & 16 & 33 & 6 \\
$(39.2 \%)$ & $(56.9 \%)$ & $(45.1 \%)$ & $(31.4 \%)$ & $(64.7 \%)$ & $(11.8 \%)$ \\
\hline \multicolumn{6}{c}{ Number of tools adopted (considering only the 5 basic tools) } \\
1 & 2 & 3 & 4 & 5 \\
$(35.3 \%)$ & 11 & 11 & 7 & 4 & \\
\hline
\end{tabular}

Source: Own elaborated based on the initiatives listed in the Consul website by mid-January 2020 (http://consulproject. $\mathrm{org} / \mathrm{en} /)$.

Successes and failures. Two examples of successful participatory activities are the proposals of "Madrid 100\% sustainable" and "Single ticket for public transport", which obtained enough support to reach the voting phase and won. Other successful practices are the participatory budgets and the poll initiated by the city council to refurbish which eleven squares, including "Plaza de España". The first 
poll and participatory budget had more participation than expected and more resources for the offline participation were needed, according to the technicians interviewed. As these were the first processes with visible results in the city, their good results were critical to gain the confidence of citizens in subsequent processes.

Civil servants 1 and 3 and Citizens 1 and 2 state that there is a problem with proposals: only two of them have reached the voting phase and a lot of them expire after receiving a lot of support (e.g., "Massive planting of trees in Madrid" with 20,602 supports of 27,662 required). Furthermore, some citizens seem to be using participatory budgets to present previous proposals that were unsuccessful in order to avoid the minimum support required for proposals. Regarding debates and processes, Citizens 1, 2 and 4 express the difficulty of following the dialogues and indicate that they are often just a confrontation of opinions without any real contribution or argumentation. Some citizens indicate that many of the debates and proposals are used by citizens to make a punctual criticism when they are angry about a public service or issue, but without greater implications. In addition, there are processes with no comments (e.g., "Project for the regulation of the organization and operations of the San Ildefonso school").

Citizens 1, 2 and 3 indicate that they do not perceive any gratitude for their participation, that they do not see the impact of their contributions in decision-making processes, or that it often takes a long time to see the result of their participation. Some citizens also indicate that, in some cases, the low participation and the possibility of external influences raise questions around the legitimacy of the results and demotivate their participation. Citizens 1 and 2 also express their concern about the high cost of some participation processes.

\section{Discussion}

Based on the case study findings, the relevant success factors and barriers are summarized in Table 5, by using a triple classification: (1) distinguishing among contextual, organizational and individual level factors; (2) considering whether they are more related to the ICT component, public sector context or democratic participation; and (3) differentiating among the different stages of development of the initiative (adoption, implementation and institutionalization). As can be seen, a mix of success factors has been present in all the stages of Decide Madrid. This initiative had a smooth adoption, with no significant barriers in this stage. This smooth adoption was mainly due to a mix of strong political support, favorable ICT-related factors and environmental pressure for transformation from stakeholders (normative isomorphism). The implementation has been the most critical stage, based on the number of success factors and barriers found. Its institutionalization was also favored by a good mix of success factors, the slow process of organizational change being the only significant barrier found.

The politicians and civil servants interviewed indicate three factors as being particularly relevant for the success of Decide Madrid: the high level of implication of the city council towards citizen participation, the method used to recruit the workers for that general directorate and the background of senior managers about citizen participation and ICTs. Therefore, individual and organizational factors, related to the public sector context and democratic participation dimension seem to have been the most important, as compared to contextual or ICT-related factors. The role of the Mayor was crucial in launching Decide Madrid, improving the coordination of the council areas and ensuring there was enough financial, political and managerial support to develop and run the platform. This confirms the importance of political leaders' support $[14,50]$ and the need to integrate citizen engagement with traditional structures and processes in local governments [51].

As for the barriers, organizational factors are the most critical in Decide Madrid. Most of them are related to the need to improve how the city council deals with some basic aspects related to democratic participation (e.g., transparency-related issues and feedback) and the slow process of organizational change inherent in the public sector context, although some barriers related to the ICT and democratic 
dimensions (lack of moderation or other mechanisms to organize debates and proposals and security concerns) have been found.

Table 5. Summary of success factors and barriers conditioning the performance of Decide Madrid.

\begin{tabular}{|c|c|c|}
\hline \multicolumn{3}{|c|}{ Panel A: Success Factors } \\
\hline Adoption & Implementation & Institutionalization \\
\hline $\begin{array}{l}\text { Contextual factors } \\
\text { - Citizen demand for more direct } \\
\text { citizen participation (15M } \\
\text { movement) (D) } \\
\text { Organizational factors } \\
\text { - Financial resources (ICT) } \\
\text { - Human resources (ICT, PS) } \\
\text { - Learning from forerunners (ICT) } \\
\text { Individual factors } \\
\text { - Strong political support (PS) }\end{array}$ & $\begin{array}{l}\text { Contextual factors } \\
\text { - Internet penetration } \\
\text { Organizational factors } \\
\text { - Previous e-government experience (ICT) } \\
\text { - Previous experience in citizen } \\
\text { participation (D) } \\
\text { - Financial resources (ICT) } \\
\text { - Human resources (ICT, PS) } \\
\text { - Staff recruitment process (PS) } \\
\text { - Creation of a particular subculture of } \\
\text { work (PS) } \\
\text { - Detailed guidelines and } \\
\text { procedures (PS, D) } \\
\text { - Coordination and collaboration with } \\
\text { other council areas (PS) } \\
\text { - Platform accessibility (ICT) } \\
\text { - Possibilities for offline participation (D) } \\
\text { - Provision of relevant information before } \\
\text { the participation (D) } \\
\text {-Integration with the policy-making } \\
\text { process (D) } \\
\text { - Influence on decision-making for } \\
\text { proposals and participatory budgets (D) } \\
\text { Individual factors } \\
\text { - Strong political support (PS) } \\
\text { - Knowledge of senior managers and } \\
\text { staff (ICT, D) }\end{array}$ & $\begin{array}{l}\text { Internal institutionalization } \\
\text { Organizational factors } \\
\text { - Integration in the policy-making } \\
\text { process (D) } \\
\text { - Coordination and collaboration with } \\
\text { other council areas (PS) } \\
\text { - Progressive change in the perception of } \\
\text { staff of other areas of government about } \\
\text { direct citizen participation (PS) } \\
\text { Individual factors } \\
\text { - Strong political support (PS) } \\
\text { External institutionalization } \\
\text { Contextual factors } \\
\text { - Country good positions in e-government } \\
\text { and e-participation rankings (ICT) } \\
\text { Organizational factors } \\
\text { - OGP Membership (PS) } \\
\text { - Open source software (ICT) } \\
\text { - Human resources (ICT, PS) } \\
\text { - Promotion (PS) } \\
\text { Individual factors } \\
\text { - Strong political support (PS) }\end{array}$ \\
\hline \multicolumn{3}{|c|}{ Panel B: Barriers conditioning the performance of Decide Madrid } \\
\hline Adoption & Implementation & Institutionalization \\
\hline & $\begin{array}{l}\text { Contextual factors } \\
\text {-Decreasing citizen interest (D) } \\
\text { Organizational factors } \\
\text { - Lack of transparency (information about } \\
\text { the internal working of the city council } \\
\text { and offline activities) (D) } \\
\text { - Lack of feedback (D) } \\
\text { - Associations not properly engaged (D) } \\
\text { - Lack of moderation or other mechanisms } \\
\text { to organize debates and proposals (D, ICT) } \\
\text { - Concerns about the security of the } \\
\text { platform and verification processes (ICT) }\end{array}$ & $\begin{array}{l}\text { Internal institutionalization } \\
\text { Organizational factors } \\
\text { - Slow process of organizational } \\
\text { change (PS) }\end{array}$ \\
\hline
\end{tabular}

Notes: ICT: factor/barrier related to information and communication technologies (ICTs); PS: factor/barrier related to the public sector context; D: factor/barrier related to democratic participation. Source: Own elaborated based on the case study findings.

The high level of Internet use in Madrid itself and the possibility of offline participation in the most significant activities carried out through the platform reduce the digital divide and related issues found in other initiatives (e.g., reference [27]) that could otherwise reduce participation and delegitimize the initiative. The restrictions of the legislative framework for citizen participation in Spain (e.g., the minimum support needed for citizens' initiatives in Spanish municipalities with more than 20,000 inhabitants is $10 \%$ of the citizens) were avoided by the commitment of the city council to take the results of the polls and participatory budgets as binding, independently of the number of participants, which has been key to its implementation and internal institutionalization. This commitment and the strong political support have also been important in the transformation of the organizational culture 
of the city council (internal institutionalization) in order to take into account citizen proposals in decision-making processes. The transformation of the organizational culture is a positive outcome that has been previously observed in some e-participation initiatives (e.g., reference [52]). However, the managers interviewed agreed that the transformation of the organizational culture is a slow process that may cause some delays in the implementation of winning projects, insufficient communication with citizens, lack of coordination among different services and units and insufficient collaboration of some of them with Decide Madrid.

The features of the Consul software and promotional activities carried out by the city council have resulted in an active international network of public sector entities interested in e-participation that collaborate to improve the platform and in a positive image of Decide Madrid. This wide adoption of the software by other institutions (external institutionalization) could be considered an example of institutions imitating leading organizations practices to achieve recognition (mimetic isomorphism) [28] or be the result of an informed and rational decision to adopt a proven and freely available technology rather than develop a new one. The analysis of the tools adopted by these entities suggest that the second option is the most feasible, as only a limited number of entities have copied the full structure of Decide Madrid. Most of them have implemented 1-3 of the tools, and even 6 entities have created additional new modules, depending on their needs. Furthermore, participatory budgeting, which according to the analysis carried out is the most successful tool, has been the most widely adopted one. Further qualitative research analyzing the e-participation experiences of these institutions would be quite interesting.

Transparency and communication seem to be the most important problems of Decide Madrid. All citizens interviewed agree that their most important motivation is the possibility of seeing their contributions implemented or taken into account, although they note that they do not have enough information about the effect of their contributions, the results of public consultations, the progress of the projects already approved or the cancelation of debates and proposals. In fact, the monitoring of citizen participation through the platform only covers participatory budgeting. The lack of feedback is a failure previously reported in other initiatives $[14,53]$ that could easily be solved, for example, by publishing a list of the comments received with an indication of whether or not they have been taken into account and the reasons for not incorporating them. Moreover, citizens interviewed think that there is not enough information about the internal working of the city council (organization, procedures and competences) for a correct evaluation of the impact of their contributions. The lack of transparency makes it difficult to legitimate e-participation initiatives and could also negatively influence citizens' future participation levels $[19,26]$, which is a main issue for long-term e-participation initiatives.

Traditionally, citizen participation in Madrid was offline through associations, while Decide Madrid is focused on individual online citizen participation. Although associations can participate in most sections, only individual citizens are allowed to vote for proposals or participatory budgets. The lesser role attributed to the traditional participation stakeholders in Madrid municipality may be the reason behind less continued participation, because online participants are less committed than offline participants, according to the networked individualism theory [32].

Moreover, although most of the activities carried out through the platform can also be carried out offline, offline participation is not integrated into the platform. Including information about activities carried out offline in the platform, as some of the adopters of the Consul software have done, could also be a useful measure to ensure continued participation. The lack of a habit among citizens of participating in online forums and the lack of moderation or other mechanisms to organize debates and proposals seem to have had some negative effects in the debates and processes sections of Decide Madrid. This pushes many citizens to participate only on an ad-hoc basis when polls and participatory budgets are carried out. The proposals section needs a minimum threshold of participation for the citizens' proposals to reach the voting phase and only two proposals have achieved this number as of November 2019. The high expectations of citizens combined with the lack of transparency they perceive in some e-participation activities causes the feeling of "a waste of time" in both users that 
create a proposal and those who support it and contribute to explaining the decreasing citizen interest, as noted by previous research $[19,34]$. The reduction in the number of participants is an important threat, as some e-participation platforms have been closed down because of that [14,24]. However, we have to bear in mind that, because of the complex dynamics in public engagement, public expectations can sometimes rise so fast that even successful initiatives can lead to disappointment [54].

\section{Conclusions}

The purpose of this research is to identify the critical success factors of the award-winning e-participation initiative Decide Madrid and the main barriers that are conditioning its performance. This case study corroborates that the success of an e-participation initiative cannot be judged in absolute terms. Evaluations vary according to the role of the person making the assessment (internal actors usually being more positive than external stakeholders) and the criteria being used (e.g., participation levels, democratic legitimacy, transparency, influence on decision-making processes or continuity). Therefore, different criteria and perspectives need to be considered to achieve a more balanced assessment of e-participation initiatives, which validates the analytical model proposed in this research. In addition to the United Nations award, Decide Madrid can be considered successful, or at least as a benchmark e-participation initiative, because of its continuity after a change of government in the municipality and its internal and external institutionalization (the last stage of e-participation initiatives). However, as the analysis has shown, some areas for improvement also exist that should be carefully managed to improve its performance and sustainability.

This study evidences that ICT-related factors are not decisive for the success of e-participation initiatives, but can pose problems if not carefully managed. Organizational and individual factors and issues related to democratic participation seem to be more important for the success of e-participation initiatives. As the barriers found in this research are not new, there seems to be a need for practitioners to take advantage of research findings as regards success and failure factors (e.g., references [14,17]) when designing and deploying an e-participation initiative in order to maximize the chances for success. Furthermore, the elaboration, publication and/or diffusion of good practice e-participation guidelines should be actively promoted.

Although the citizens interviewed have been critical and sometimes have questioned the levels of participation and the effectiveness of Decide Madrid, both citizens and municipal staff consider that Decide Madrid is necessary, which supports the success of this initiative. This agreement among interviewees evidences the high motivation for e-participation and direct citizen participation for both the city council and the citizens, although it seems that both citizens and the city council need more time to adapt to online direct participation. Improvements in Decide Madrid based on the feedback and lessons learned from the first experiences could help increase citizen trust, participation levels, and the legitimacy of this platform among citizens. The way in which these challenges are tackled and the maintenance of the commitment to e-participation of future government teams will determine future levels of citizen participation and the viability of the initiative.

Author Contributions: Conceptualization, S.R., V.P. and J.G.-R.; methodology, S.R., V.P. and J.G.-R.; formal analysis, S.R., V.P. and J.G.-R.; investigation, S.R., V.P. and J.G.-R.; writing-original draft preparation, S.R., V.P. and J.G.-R.; writing-review and editing, S.R., V.P. and J.G.-R.; funding acquisition, V.P. and S.R. All authors have read and agreed to the published version of the manuscript.

Funding: This study has been carried out with the financial support of the European Union's Horizon 2020 research and innovation program (grant agreement No.726840, TROPICO project), the Regional Government of Aragón/FEDER 2014-2020 "Building Europe from Aragón" (project S56-17R) and the University of Zaragoza (project UZ2019-SOC-05).

Conflicts of Interest: The authors declare no conflict of interest. 


\section{References}

1. Kickert, W.J.M. Public Governance in the Netherlands: An Alternative to Anglo-American Managerialism. Public Adm. 2019, 75, 731-752. [CrossRef]

2. Stoker, G. Governance as theory: Five propositions. Int. Soc. Sci. J. 1998, 68, 15-24. [CrossRef]

3. Thomas, J.C.; Streib, G. E-Democracy, E-Commerce, and E-Research: Examining the Electronic Ties Between Citizens and Governments. Adm. Soc. 2005, 37, 259-280. [CrossRef]

4. Vragov, R.; Kumar, N. The impact of information and communication technologies on the costs of democracy. Electron. Commer. Res. Appl. 2013, 12, 440-448. [CrossRef]

5. UN. United Nations E-Government Survey 2014; UN: San Francisco, CA, USA, 2014. Available online: https://publicadministration.un.org (accessed on 15 January 2019).

6. UN. UN Global E-Government Survey 2003; UN: San Francisco, CA, USA, 2003. Available online: https: //publicadministration.un.org (accessed on 15 January 2019).

7. UN. UN E-Government Survey 2018; UN: San Francisco, CA, USA, 2018. Available online: https: //publicadministration.un.org (accessed on 15 January 2019).

8. OECD. Promise and Problems of E-Democracy: Challenges of Online Citizen Engagement; OECD: Paris, France, 2003. Available online: http://www.oecd.org/ (accessed on 3 February 2019).

9. Bonsón, E.; Torres, L.; Royo, S.; Flores, F. Local e-government 2.0: Social media and corporate transparency in municipalities. Gov. Inf. Q. 2013, 29, 123-132.

10. Brainard, L.A.; McNutt, J.G. Virtual Government-Citizen Relations: Informational, Transactional, or Collaborative? Adm. Soc. 2010, 42, 836-858. [CrossRef]

11. Criado, J.I.; Rojas-Martín, F. Adopting Social Media in the Local Level of Government: Towards a Public Administration 2.0? In Social Media and Local Governments: Theory and Practice; Sobaci, M.Z., Ed.; Springer International Publishing: Cham, Switzerland, 2016; pp. 135-152.

12. Norris, D.F.; Reddick, C.G. Local E-Government in the United States: Transformation or Incremental Change? Public Adm. Rev. 2013, 73, 165-175. [CrossRef]

13. Royo, S.; Yetano, A.; Acerete, B. E-Participation and Environmental Protection: Are Local Governments Really Committed? Public Adm. Rev. 2014, 74, 87-98. [CrossRef]

14. Toots, M. Why E-participation systems fail: The case of Estonia's Osale.ee. Gov. Inf. Q. 2019, 36, 546-559. [CrossRef]

15. Falco, E.; Kleinhans, R. Beyond technology: Identifying local government challenges for using digital platforms for citizen engagement. Int. J. Inf. Manag. 2018, 40, 17-20. [CrossRef]

16. Le Blanc, D. E-Participation: A Quick Overview of Recent Qualitative Trends; Working Paper No. 163; United Nations DESA: New York, NY, USA, 2020. Available online: https://www.un.org/ (accessed on 30 January 2020).

17. Panopoulou, E.; Tambouris, E.; Tarabanis, K. Success factors in designing eParticipation initiatives. Inf. Organ. 2014, 24, 195-213. [CrossRef]

18. Sæbø, Ø.; Rose, J.; Flak, L.S. The shape of eParticipation: Characterizing an emerging research area. Gov. Inf. Q. 2008, 25, 400-428.

19. Font, J.; Navarro, C. Personal experience and the evaluation of participatory instruments in Spanish cities. Public Adm. 2013, 91, 616-631. [CrossRef]

20. Wirtz, B.W.; Daiser, P.; Binkowska, B. E-participation: A Strategic Framework. Int. J. Public Adm. 2016, 41, 1-12. [CrossRef]

21. Steinbach, M.; Sieweke, J.; Süß, S. The diffusion of e-participation in public administrations: A systematic literature review. J. Organ. Comput. Electron. Commer. 2019, 29, 61-95. [CrossRef]

22. Medaglia, R. eParticipation research: Moving characterization forward (2006-2011). Gov. Inf. Q. 2012, 29, 346-360. [CrossRef]

23. Reddick, C.; Norris, D.F. E-participation in local governments: An examination of political-managerial support and impacts. Transform. Gov.Peopleprocess Policy 2013, 7, 453-476. [CrossRef]

24. Sæbø, Ø.; Flak, L.S.; Sein, M.K. Understanding the dynamics in e-Participation initiatives: Looking through the genre and stakeholder lenses. Gov. Inf. Q. 2011, 28, 416-425.

25. Sæbø, Ø.; Rose, J.; Molka-Danielsen, J. eParticipation: Designing and Managing Political Discussion Forums. Soc. Sci. Comput. Rev. 2010, 28, 403-426. [CrossRef] 
26. Sjoberg, F.M.; Mellon, J.; Peixoto, T. The Effect of Bureaucratic Responsiveness on Citizen Participation. Public Adm. Rev. 2017, 77, 340-351. [CrossRef]

27. Meneses, M.E.; Nonnecke, B.; del Campo, A.M.; Krishnan, S.; Patel, J.; Kim, M.; Crittenden, C.; Goldberg, K. Overcoming citizen mistrust and enhancing democratic practices: Results from the e-participation platform México Participa. Inf. Technol. Int. Dev. 2017, 13, 138-154.

28. DiMaggio, P.J.; Powell, W.W. The Iron Cage Revisited: Institutional Isomorphism and Collective Rationality in Organizational Fields. Am. Sociol. Rev. 1983, 48, 147. [CrossRef]

29. Mergel, I. Social media adoption and resulting tactics in the U.S. federal government. Gov. Inf. Q. 2013, 30, 123-130. [CrossRef]

30. Pina, V.; Torres, L.; Royo, S. Comparing online with offline citizen engagement for climate change: Findings from Austria, Germany and Spain. Gov. Inf. Q. 2017, 34, 26-36. [CrossRef]

31. Royo, S.; Yetano, A.; Acerete, B. Citizen Participation in German and Spanish Local Governments: A Comparative Study. Int. J. Public Adm. 2011, 34, 139-150. [CrossRef]

32. Rainie, L.; Wellman, B. Networked. The New Social Operating System; The MIT Press: Cambridge, MA, USA, 2012.

33. Castells, M. The Internet Galaxy: Reflections on the Internet, Business, and Society; Oxford University Press: Oxford, UK, 2001.

34. Yetano, A.; Royo, S. Keeping Citizens Engaged: A Comparasion Between Online and Offline Participants. Adm. Soc. 2017, 49, 394-422. [CrossRef]

35. Gelders, D.; Brans, M.; Maesschalck, J.; Colsoul, N. Systematic evaluation of public participation projects: Analytical framework and application based on two Belgian neighborhood watch projects. Gov. Inf. Q. 2010, 27, 134-140. [CrossRef]

36. Porwol, L.; Ojo, A.; Breslin, J.G. An ontology for next generation e-Participation initiatives. Gov. Inf. Q. 2016, 33, 583-594. [CrossRef]

37. Kubicek, H.; Aichholzer, G. Closing the evaluation gap in e-participation research and practice. In Evaluating E-Participation: Frameworks, Practice, Evidence; Aichholzer, G., Kubicek, H., Torres, L., Eds.; Springer International Publishing: Cham, Switzerland, 2016; pp. 11-45.

38. Randma-Liiv, T.; Vooglaied, K.M. Organizing for E-Participation: Comparing European Experiences. Deliverable D5.2. Tropico Project. 2019. Available online: https://www.tropico-project.eu (accessed on 20 December 2019).

39. Yin, R.K. Case Study Research. Design and Methods; Sage: London, UK, 2014.

40. Bingham, L.B.; Nabatchi, T.; O'Leary, R. The new governance: Practices and processes for stakeholder and citizen participation in the work of government. Public Adm. Rev. 2005, 65, 547-558. [CrossRef]

41. European Commission. E-Government in Spain; European Commission: Brussels, Belgium, 2018. Available online: https://joinup.ec.europa.eu (accessed on 15 January 2019).

42. UN/ASPA. Benchmarking E-government: A Global Perspective; UN: San Francisco, CA, USA, 2001. Available online: https://publicadministration.un.org (accessed on 15 January 2019).

43. INE. Encuesta sobre equipamiento y uso de tecnologías de información y comunicación en los hogares 2017 [Data set]. 2018. Available online: https://www.ine.es (accessed on 17 January 2019).

44. Pina, V.; Torres, L.; Royo, S. Are ICTs improving transparency and accountability in the EU regional and local government? An empirical study. Public Adm. 2007, 85, 449-472. [CrossRef]

45. Sánchez, G.; Pastor, G. The Quality of Participatory Processes in the Urban Redevelopment Policy of Madrid City Council. Lex Localis J. Local Self-Gov. 2018, 16, 841-872. [CrossRef]

46. OGP. Madrid, Spain. 2018. Available online: https://www.opengovpartnership.org/countries/madrid-spain (accessed on 20 December 2018).

47. Europa Press. Cs critica que el proceso participativo de Ahora Madrid no cumple con garantías de confidencialidad y recuento electoral (02/02/2017). Available online: https://www.europapress.es (accessed on 14 December 2018).

48. Ayuntamiento de Madrid. Acuerdo de 29 de octubre de 2015 de la Junta de Gobierno de la Ciudad de Madrid de Organización y Competencias del Área de Gobierno de Participación Ciudadana: Transparencia y Gobierno Abierto; No. 7.530; Boletín Oficial del Ayuntamiento de Madrid: Madrid, Spain, 2015.

49. Ayuntamiento de Madrid. Portal de Datos Abiertos del Ayuntamiento de Madrid [Data Set]; Ayuntamiento de Madrid: Madrid, Spain, 2019. Available online: https://datos.madrid.es (accessed on 1 July 2019). 
50. Panopoulou, E.; Tambouris, E.; Tarabanis, K. E-Participation Initiatives in Europe: Learning from Practitioners. In Lecture Notes in Computer Science; Springer Science+Business Media: Berlin, Germany, 2010; Volume 6229, pp. 54-65.

51. Nalbandian, J.; O’Neill, R.; Wilkes, J.M.; Kaufman, A. Contemporary Challenges in Local Government: Evolving Roles and Responsibilities, Structures, and Processes. Public Adm. Rev. 2013, 73, 567-574. [CrossRef]

52. Tambouris, E.; Macintosh, A.; Smith, S.; Panopoulou, E.; Tarabanis, K.; Millard, J. Understanding eParticipation State of Play in Europe. Inf. Syst. Manag. 2012, 29, 321-330. [CrossRef]

53. Royo, S.; Yetano, A. "Crowdsourcing” as a tool for e-participation: Two experiences regarding CO2 emissions at municipal level. Electron. Commer. Res. 2015, 15, 323-348. [CrossRef]

54. Mulgan, G. Reshaping the state and its relationship with citizens: The short, medium and long-term potential of ICTs. In The network Society. From Knowledge to Policy; Castells, M., Cardoso, G., Eds.; Johns Hopkins Center for Transatlantic Relations: Washington, DC, USA, 2015; pp. 225-238.

(C) 2020 by the authors. Licensee MDPI, Basel, Switzerland. This article is an open access article distributed under the terms and conditions of the Creative Commons Attribution (CC BY) license (http://creativecommons.org/licenses/by/4.0/). 